\title{
Círculos Literarios de Iberoamérica
}

\author{
(ESTUDio PRELIMINAR)
}

T OS círculos, tertulias, sociedades y academias literarias de Iberoamérica son una continuación de las reuniones literarias de España, llegadas a la Península Ibérica de Francia (Provence) o de Italia, cuna en último término de todas estas asambleas intelectuales de pasatiempo. En España florecen en la primera parte del siglo xvir, aunque sus orígenes se remontan a mediados del anterior. ${ }^{1}$

Las sociedades de carácter comercial y fomento nacional se instituyen en España en 1764 con la bien conocida Sociedad Vascongada para Fomentar el Gusto de las Bellas Letras. Este tipo de Sociedad sirve de modelo para las numerosas Sociedades Económicas del país, o de los Amigos, que en tiempos coloniales se encuentran dispersas en casi todas las capitales de Hispanoamérica. La Sociedad Económica en América es de especial significado porque no sólo fomenta el desarrollo de la industria y del comercio nacional, sino que es con frecuencia centro de conspiración, bien contra el gobierno, o bien contra la vigilancia gubernamental para dejar entrar al país nuevas ideas libertadoras. Es, otras veces, como en el caso de Cuba, un potente organismo que estimula las voluntades para el cultivo y desarrollo de la propiedad del país.

Bastante se ha escrito sobre la vida intelectual de Iberoamérica, pero muy poco sobre las reuniones y asambleas literarias y su influencia en la literatura y en el desarrollo intelectual del continente. Los críticos se limitan a referencias de pasada. Un estudio serio y definitivo sobre este tema se hace más indispensable cada día a medida que el campo de la vida intelectual de la América española se explora y ensancha. Para llevar a cabo tal estudio hay que examinar 
los muchos manuscritos y obras inéditas existentés en bibliotecas públicas y privadas. ${ }^{2}$

Excluimos por ahora de este estudio preliminar las academias de carácter oficial, que a semejanza de las distintas instituciones francesas y españolas se vinieron fundando en casi todas las capitales de Iberoamérica. ${ }^{3}$ También se excluyen las academias de carácter puramente docente. Estamos interesados en los centros, tertulias, sociedades y demás reuniones informales de literatos o aficionados a que los hombres de letras recurrían para regocijo propio y ajeno. Estas reuniones de poetas y escritores han sido muy corrientes desde el establecimiento de los virreinatos, pero han florecido mayormente de fines del siglo xvinI en adelante.

En tiempos coloniales siempre hubo fiestas para celebrar algún acontecimiento público. La toma de posesión de un virrey, la tardía. noticia del ascenso o muerte del rey en España, o la canonización de algún santo, cualquiera de estos sucesos daba ocasión a regocijos. y celebraciones públicas y certámenes poéticos. Las composiciones. presentadas en estos concursos eran a menudo de forma muy caprichosa y de mal gusto. ${ }^{4}$ Estos festivales solían celebrarse ya en los salones del palacio del virrey, ya en la universidad, o bien en la. catedral, o en los tres a la vez. Concurría lo más granado de la ciudad y del reino, y estos actos se tomaban muy en serio, celebrándose en México, Bogotá y Lima con gran esplendor y pompa.

La literatura y la historia hispanoamericana están llenas de referencias a estos certámenes públicos de carácter temporal. Mencionaremos algunos de los más notables a modo de ejemplo. Con motivo del Tercer Concilio Provincial Mexicano, en 1585, concurrieron a la capital y tomaron parte en el concurso poético celebrado más de trescientos poetas. Entre ellos estaba Bernardo de Balbuena, quien fué laureado por una de sus composiciones. La ciudad de Tunja, en Colombia, celebró el 18 de enero de 1663 el nacimiento del Príncipe Carlos José. ${ }^{5}$ En su rara obra Triumpho Parthenico, publicada en México en 1683, el sabio mexicano Carlos de Sigüenza y Góngora describe y comenta dos famosas fiestas y justas literarias convocadas por la "Pontificia y Regia Academia Mexicana" en 1682 y 1683 para festejar "el misterio piadoso de la concepción purísima de María". Pedro de Peralta Barnuevo, además de dirigir una academia de matemáticas, también "dirigía certámenes y otras funciones más o menos públicas". "La Universidad de San Marcos, desde. 
tiempos remotos, acostumbraba celebrar certámenes literarios que solían ser solemnes celebraciones pomposas donde brillaba la intelectualidad contemporánea. Una de estas fiestas más célebres fué la organizada para recibir al nuevo virrey don Manuel de Amat y Junient, en 1761. ${ }^{7}$ El Certamen de Almendares, celebrado el $1^{\circ}$ de mayo de 1834, a corta distancia de la Habana, fué un festín campestre dado en honor de Martínez de la Rosa con motivo de su nuevo puesto en el gobierno de España. ${ }^{8} \mathrm{Hubo}$ bellas ninfas, jóvenes vates que leyeron sus composiciones desde un templo, se coronaron unos a los otros, y entre vítores y vivas los treinta y cinco o cuarenta concurrentes pasaron una tarde de mụcha alegría a la orilla del Arroyo Apolo. Ninguno de los poetas que tomaron parte llegó a adquirir renombre más tarde. En tiempos más recientes ha habido otros certámenes de bastante consideración, como son el Certamen Varela, celebrado en Santiago de Chile en 1887 y el Certamen nacional científico y literario, celebrado en 1877 en Caracas, por disposición del gobierno.

El gusto literario de los virreyes y la protección que dispensaban. a las letras también son factores decisivos en el desarrollo de las tertulias y círculos literarios, sobre todo en las cortes virreinales. E1 ocio de la juventud colonial también fomentaba los ejercicios disciplinarios mentales, y de ahí que se discutiera y se disertara tanto el pro y el contra sobre temas muy diversos, ya de palabra, ya por escrito. La juventud, aposentada en la corte, o en las provincias del interior, carecía de atenciones que la distrajeran y ardía continuamente en un deseo querellante que servía de pasatiempo y de satisfacción espiritual. Al recorrer a Nueva Granada en 1801, dice Alejandro Humboldt que había en el país una efervescencia intelectual: "el deseo de poseer libros y de conocer nombres de los hombres célebres." 9

A fines del siglo xviri se empezó a dar una forma más regular y permanente a las reuniones de los aficionados a las letras. Patrocinados por el virrey se solían remir escritores, poetas y demás hombres de letras y ciencias por distracción estética a la vez que para fomentar las letras. De estas reuniones - domésticas al principio- resultaron las academias y sociedades virreinales que florecieron en muchas ciudades, a pesar de los obstáculos y restricciones de libros e imprenta. Por eso dice Pimentel ${ }^{10}$ que la curiosidad intelectual en tiempos coloniales no podía satisfacerse con los estudios. 
ofrecidos en los centros docentes. Estos eran muy reglamentados y sin duda bastante áridos.

Con el reinado de Carlos III la vida intelectual de las colonias adquiere características propias. Carlos III concede a la América española un nuevo rumbo de administración y vida. Obtuvieron las colonias más libertad de comercio, se reorganizaron los consulados, se fundaron otros virreinatos. En suma: después de la revolución francesa, del advenimiento de Napoleón y de la independencia de los Estados Unidos, el pueblo americano ya no puede resistir el ámbito enclaustrado en que había vivido hasta entonces. Germinan las revoluciones, se prepara la emancipación, se sublevan los pueblos. Entonces van apareciendo los grandes patriotas y los grandes escritores. Hubo una pléyade de estos próceres hispanoamericanos, hombres sabios, inquietos, deseosos de nuevos experimentos y de conocer el más allá. Se reunían en sociedades, unas veces públicas, otras secretas. Estas sociedades, a veces disfrazadas como centros literarios, los grandes maestros y el periodismo fueron sin duda los tres grandes factores que contribuyeron al fomento intelectual en los últimos años coloniales y como resultado directo de tal sublevación espiritual apareció la generación de la independencia.

A imitación de análogas sociedades europeas hubo en la América española un sinfín de sociedades secretas, tema que no se desea desarrollar aquí. No obstante, están relacionadas con las literarias, pues en muchos casos éstas se convierten en sociedades secretas o de carácter político. La más célebre de estas sociedades es la Asociación de Mayo, organizada el 23 de junio de 1837 en Buenos Aires, por Esteban Echeverría, Juan María Gutiérrez y Juan Bautista Alberdi, los tres grandes espíritus rebeldes de su época. En Colombia florecieron algunas sociedades de carácter político, cono fué La Filotécnica, integrada por jóvenes, en su mayor parte, y la Sociedad Popular, que existían en Bogotá a mediados del siglo xix. Las Sociedades Democráticas, también de Bogotá, eran patrocinadas por el gobierno para instruir a sus habitantes sobre asuntos políticos.

En Cuba, la Real Sociedad Económica de la Habana ha sido desde su fundación un organismo de poderosa influencia en asuntos no sólo económicos sino literarios. Ha promovido toda clase de adelantos; ha velado por la enseñanza pública; ha instigado el establecimiento de la primera biblioteca pública en la Habana; ha tenido poderes casi absolutos en la enseñanza de la Isla. En tiempos colonia- 
les fué esta Sociedad algo así como cuerpo consultivo de las autoridades civiles. Conocida también por Sociedad Patriótica de la Habana y Sociedad Económica de Amigos del pais, 11 "sus afanes determinan la corriente de ideas que agita a nuestra soñolienta sociedad colonial y la pone en comunicación con el espíritu del tiempo nuevo". ${ }^{12}$

Aunque no la primera en Cuba, pues ya en 1788 se había constituído una Sociedad de Amigos del Pais en Santiago, la cual fracasó por falta de interés, la de la Habana fué fundada por real orden del 15 de diciembre de 1792 e inaugurada el 9 de enero de 1793; es todavía una de las más influyentes sociedades en la vida intelectual de Cuba. ${ }^{13}$ Se reunió por primera vez en el palacio del gobierno, bajo la presidencia del capitán general don Luis de las Casas. Su primer director fué el distinguido prelado doctor Luis Peñalver y Cárdenas. José de Arango y Castillo fué bibliotecario por algún tiempo. En sus principios tenía fines más patrióticos que culturales; ahora éstos se invierten. En 1794 tomó dicha Sociedad a su cargo la publicación del famoso Papel Periódico, que había sido fundado en 1790. En 1805 cambió el citado periódico su título por el de Aviso y en 1810 pasó a ser Diario de la Habana. ${ }^{14}$ Además de tal empresa periodística, la Sociedad publicaba mensualmente y por cuadernos sus Memorias, "una de las publicaciones que más influyeron en la cultura de la isla”, dice Menéndez y Pelayo. ${ }^{15}$

En el campo literario esta Sociedad publicó la Revista y Repertorio Bimestre de la Isla de Cuba, que pronto cambió su nombre a Revista Bimestre Cubana, una de las mejores revistas en español, que todavía se publica. Dentro de la misma Sociedad se estableció en 1811 la Academia de Dibujo y Pintura, que bajo la dirección de Alejandro Ramírez llegó a ser un importante centro de bellas artes.

Los individuos de número de la comisión permanente de literatura de la Real Sociedad Económica solicitaron al gobierno de $\mathrm{Ma}$ drid que se les permitiese constituirse en academias independientes de tal corporación, "con el objeto de fomentar en esa isla la afición al estudio de las humanidades, y el conocimiento de las obras clásicas nacionales en todos ramos". 16 Por Real Orden del 25 de diciembre de 1833 se constituyó la Academia de Literatura Cubana. Tuvo su primera reunión el 6 de mayo de 1834, en la residencia de su presidente don Nicolás de Cárdenas y Manzano, pero por impedimento del general Miguel de Tacón no se llevó a completo desarrollo este magno proyecto. ${ }^{17}$ 
En el siglo xix hubo otros círculos de fines literarios en la capital de Cuba, entre los que merecen mencionarse El Liceo de la Habana, que publicaba un semanario del mismo nombre entre 1857 y 1867. Joaquín Lorenzo Luaces fué uno de sus socios y se le premió en 1867 por una oda presentada en unos juegos florales organizados por dicho Liceo. E1. propio Luaces trata en sus Noches literarias en casa de Nicolás Azcárate ${ }^{18}$ de la Tertulia de Nicolás Azcárate, que se celebraba en la Habana, compuesta de los próceres más eminentes de la mitad del siglo. "A partir de 1870 fomentó reuniones en su casa, protegió a Mendive, fomentó el movimiento separatista, aunque era conservador, y mandó reunir los resultados de las reuniones de su casa en el volumen Noches literarias en casa de Nicolás Azcárate." ${ }^{19}$ El Liceo Artístico y Literario también era otro círculo que florecía casi en la misma fecha. Publicaba El Artista, redactado por J. Q. Suzarte y Andrés Poey.

Matanzas ha sido siempre una ciudad bastante intelectual. Siempre ha estado interesada en tertulias literarias. Bien conocidos son El Club de Matanzas, que en sus últimos años cambió su nombre por El Liceo de Matanzas, y El Ateneo, con periódico del mismo nombre redactado por Fernando Ranero Fajardo, de 1879 a 1883. El Club de Matanzas también tenía su propio semanario de ciencias, literatura y bellas artes, que se publicó, con el mismo nombre, de 1879 a 1882, con una corta interrupción. Al convertirse el Club en Liceo, también lo hizo su órgano.

En Santo Domingo han existido tertulias y círculos literarios desde hace mucho tiempo, pero se tienen escasos datos sobre tales centros. A mediados del siglo xix hubo un grupo de poetas en la capital dominicana que se reunían en sociedades de aficionados, y entre las más conocidas figura la llamada Los Amantes de las Letras. ${ }^{20}$ Entre las personas que frecuentaban ésta y otras sociedades, se pueden mencionar Félix María del Monte y Josefa Antonia Perdomo y Heredia. Las sociedades Liga de la Paz, Amantes de la Luz, Amigos del Pais florecieron en los veinticinco años finales del siglo pasado. Parece ser que la última de estas tres era la más activa, pues estableció conferencias literarias y subvencionó la publicación de muchas. obras, como la Historia de Santo Domingo, de Antonio del Mónte y Tejada. Su labor cultural "alcanzó su apogeo hacia 1880 y fué activísima. Allí figuraban Emilio Prud’home y José Dubeatu, educa- 
dores y poetas; Pablo Pumarol... César Nicolás Pensón”. ${ }^{21}$ La Sociedad Amantes de la Luz se convirtió más tarde en La Republicana.

En Puerto Rico, el centro más notable del siglo xix parece ser el Ateneo de Puerto Rico, fundado en 1876 por instigación de Manuel Elzaburu. Es célebre dicha asamblea por sus certámenes anuales y estudios de divtulgación científica. Entre los hombres de letras que frecuentaban el Ateneo son dignos de mención Giménez Sanz, Padilla, Tapia y Rivero, Corchado, Romero, Peñaranda, Regúlez, Sánchez Pesquera, García Salgado, Gautier, etc.

En las cortes virreinales, las asociaciones de hombres de letras empezaron con la llegada de los gobernantes amantes de las letras. Ellos protegían y alentaban a los poetas. Dice el Marqués de Valmar que en el siglo xviı resonaba "en el palacio del elegante e ilustrado virrey Marqués de Mancera, de México, el discreteo ingenioso a par que alambicado de la afamada monja mejicana Sor Juana Inés de la Cruz". ${ }^{22}$ En México hubo otros virreyes protectores de las letras, pero ninguno organizó Sociedad o Academia de carácter permanente semejante a la Tertulia del Marqués Castell-dos-Ruis o la del Príncipe de Esquilache, ambas en Lima. Si las hubo en México, nada se sabe hasta ahora. Sí hubo frecuentes certámenes literarios, como el organizado por el deán de la catedral don José Mariano Beristain de Souza en $1803,{ }^{23}$ y otros ya mencionados y por mencionar.

Pasando por alto las Academias de carácter docente, como la famosa Academia de San Carlos de Nueva España, llamađa también de las tres nobles artes, ${ }^{24}$ nos internamos en el siglo Xix, que, como en los demás países hispanoamericanos, excepto el Perú, es el período de florecimiento de los círculos literarios. La Arcadia Mexicana fué interesante centro de reunión de artistas y literatos en la capital mexicana. Fué fundada en 1808, por el franciscano de Michoacán Manuel de Navarrete. Al famoso Lizardi se le debe el proyecto de la Sociedad Pública de Lectura, que aunque no era una tertulia literaria en su sentido estricto, fué, no obstante, una reunión de personas afanosas en las letras. La Academia de Letras, fundada en 1836 en la ciudad de México, tuvo mucha influencia en los escritores de su tiempo. Entre sus más eminentes socios se contaba el costumbrista Guillermo Prieto.

De mayor significado en las letras mexicanas fué El Ateneo Mexicano, fundado en la capital en 1840 por José Gómez de la Cortina, 
Angel Calderón de la Barca, Francisco Ortega y otros. Contaba con un semanario del mismo nombre que el centro, y entre sus redactores figuraban José M. Lacunza, Lucas Alamán, Andrés Quintana Roo, José M. Lafragua y Guillermo Prieto.

La Academia de San Juan de Letrán merece especial mención, pues a ella pertenecieron la mayoría de los escritores de mediados del siglo xix y antes. El poeta español José Zorrilla dice acerca de esta academia:

Dividida más tarde en dos bandos la academia de San Juan, sus discusiones produjeron dos periódicos literarios, El Liceo y El Museo; al primero fueron a escribir Franco, poeta mediano, pero de gran capacidad, hombre de vasta erudición y clarísimo talento, Martinez de Castro, Navarro y Alcaraz; El Museo le redactaron casi exclusivamente Payno y Prieto, ya bajo su firma, ya bajo varios seudónimos. 25

En 1836 ingresó a esta tertulia Ignacio Ramírez, "E1 Nigromante", gran orador de raza india que llegó a ocupar influyentes puestos públicos en el gobierno mexicano. Altamirano también fué socio de la agrupación. Guillermo Prieto debe sus orígenes literarios a la influencia de la Academia de San Juan de Letrán. Allí alternó con Carpio y Pesado, Quintana Roo, Alejandro Arango, y Escandón y otros.

Con el nombre azteca Netzahualcóyotl funcionaba esta sociedad literaria en México, en 1869. El Anáhuac era su órgano oficial. ${ }^{26}$ Fué fundada dicha sociedad por Manuel Acuña, de Saltillo, quien a los 19 años de edad marchó a la capital a estudiar medicina. También por el mismo tiempo existía en la metrópoli mexicana la Sociedad de Libre Pensadores, grupo literario establecido el 5 de mayo de 1870 ; tenía su propio periódico, El Libre Pensador, dirigido por Pedro Batiza. Por esos mismos años había en la capital otro círculo literario llamado Bohemia Literaria. También tenía su propio órgano oficial, La Linterna Mágica, que apareció semanalmente en 1872, redactado por José T. de Cuéllar. Cuéllar, quien escribía con el seudónimo de Facundo, también usó el título La Linterna Mágica en una colección de artículos y novelas de costumbres, publicados separadamente.

Otra sociedad literaria de bastante influencia fué El Liceo $\mathrm{Hi}$ dalgo. En 1884 publicaba su propio periódico, con igual nombre. 
Altamirano, hombre de muchas y provechosas actividades literarias, y fundador de varias sociedades de igual género, asistía al Liceo Hidalgo y contribuía a su periódico. Fué él quien restableció el Liceo en época de decadencia. A medida que la antigua Academia de San Juan de Letrán iba decayendo, el Liceo se robustecía con la presencia de jóvenes ingenios que más tarde iban a ser los grandes escritores del fin del siglo. El Liceo Mexicano, existente en la misma época que el Hidalgo, publicó un periódico quincenal de igual nombre, de 1885 a 1889 . Peña y Reyes contribuía con su asistencia y con sus trabajos poéticos. González Obregón también publicó en la revista algunos de sus artículos. Al final del siglo XIx hubo otras congregaciones de aficionados a las letras, pero hasta ahora apenas se conocen sus nombres.

Fuera de la capital mexicana, es digna de mencionarse la Alianza literaria y científica de Guadalajara, que existía en 1876. Publicaba un periódico. La Aurora Literaria, de la misma ciudad, también contaba con un semanario, publicado desde 1877 hasta 1881. En Monterrey se tienen noticias de la Sociedad Florencio del Castillo, con órgano quincenal, El Horario, publicado en 1878. ${ }^{27}$

Por ser Guatemala capitanía de bastante consideración política, también se desarrolló allí el gusto literario, aunque nunca al grado a que llegó en las capitales virreinales. La vida intelectual y literaria de la región de Guatemala, por otra parte, estuvo grandemente circunscrita a la Sociedad Económica de Amigos del País, que, como en el caso de la de la Habana, tenía al principio fines económicos. Fué dicha Sociedad fruto del oidor Jacobo de Villa Urrutia, quien desde el 27 de agosto de 1794 congregaba en su propia casa a sus ilustres amigos literatos. Se considera establecido este centro a partir del 27 de mayo de 1795, pues en ese día se leyó el proyecto de estatutos, que fué aprobado más tarde por el rey. A la apertura concurrieron próceres como fray José Antonio de Liendo y Goicochea, piadoso e incansable maestro, don Martín Barruntia y Pedro GarciAguirre. Llamada también Real Sociedad Patriótica de Guatemala, parece haber sido la segunda de este género establecida en tierra firme. Tenía por fin fomentar y difundir los conocimientos de las artes, de la agricultura, industria y economía. Auspició el estudio de la flora y fauna guatemaltecas. También estableció la Sociedad una escuela de dibujo y otra de matemáticas. "Impulsó el progreso nacional en todos los ramos, difundió luces y prodigó estímulos u 
otorgó permiso, anticipándose de tal modo a veces a su tiempo, que aún quedan útiles iniciativas de dicha entidad por realizarse." 28 Por recelos del gobierno fué suspendida dicha entidad, por orden ministerial del 25 de noviembre de 1799. Contaba entonces entre sus miembros a todos los intelectuales del reino y muchos distinguidos extranjeros, como el virrey de México. Fué restablecida por decreto del 12 de julio de 1810 y continuó su obra patriótica por muchos años. Allá por 1828, los miembros de la Sociedad se hallaban alejados unos de otros y la Sociedad casi moribunda. En 1829 el gobierno le dió nueva vida con nuevo personal, pero fué definitivamente disuelta en 1881. Ya en 1879 se había decretado que sus libros y salones formaran parte de la Biblioteca Nacional. ${ }^{29}$ Fué esta Sociedad muy activa en asuntos literarios. Casi todos los grandes hombres de Guatemala fueron socios, entre los que cabe citar, además de Villa Urrutia, a Córdoba, Valle, Goicochea Larrane, Dighero, Rayón y otros. Con la desaparición de la Sociedad Económica de Amigos del Pais continuó su obra cultural la sociedad El Porvenir, que ocupó parte de su edificio y el mobiliario.

En Caracas también se establecieron Sociedades Económicas con los mismos fines que las anteriores, pero también interesadas en el progreso cultural del país. La Sociedad Patriótica de Caracas, sugerida por Bolívar y creada por la primera Junta de Caracas por decreto de 1811, fué más bien una sociedad económica y revolucionaria. La de los Amigos del País, también de Caracas, se interesaba en el mejoramiento de la industria y en el fomento y desarrollo de la riqueza nacional y comercial; pero hizo grandes esfuerzos en el campo cultural. Ha habido en Venezuela muchas agrupaciones de más carácter literario que las anteriores, como el Centro Científico-Literario de Ciudad Bolivar, con publicación propia (Horizontes), ${ }^{30} \mathrm{y}$ Alegría, en Coro, también con órgano de publicidad (Flores y Letras, 1893), pero hasta ahora son muy escasos los datos acerca de tales tertulias y círculos literarios.

La región de los Andes, a pesar de su aparente aislamiento, fué más rica en estas asambleas y se conservan más datos sobre las mismas. Había en dicha región tres centros literarios: Bogotá, Quito y Lima. En el sur del continente, como ya veremos, el foco intelectual se dividía entre Santiago de Chile y Buenos Aires. La importancia política de todas estas ciudades atraía a los estudiosos y aficionados a las letras. El interés literario en Bogotá, Lima y Quito se 
alentaba por el creciente número de libros e ideas extranjeros que cada vez más penetraban en la colonia a pesar de estar aquéllos prohibidos. A su regreso de Europa, José Baquíjano y Carrillo aportó a la capital limeña gran número de libros prohibidos, sobre todo obras de Voltaire, Rousseau, Montesquieu, Diderot, Bayle, La Mettre, etc. ${ }^{31}$ Todo esto da un impulso renovador a la vida intelectual colonial y sobre todo a la literatura. Como ha dicho Vergara y Vergara, los círculos literarios de Santa Fe "forman la historia de nuestras letras en su más gloriosa época”. ${ }^{32}$

A medida que el teatro y el periodismo se desarrollan en Bogotá, también se fomenta el espíritu literario. Los círculos literarios que entonces se establecieron ofrecían a la juventud estudiosa lugar de reunión para estimular su ansia de saber. Al principio del siglo XIX hubo en Bogotá un grupo de intelectualidades formado por una selecta sociedad de los hombres más eminentes de aquel tiempo. El vulgo llamaba a este grupo con el apodo de Compañia de los Sabios; no formaban círculo, pero sirve de punto de partida a los que más tarde se establecieron con carácter más permanente. Entre los Sabios estaban José María Salazar, José Fernández Madrid, José María Cabal, Joaquín Camacho, Frutos Joaquín Gutiérrez y otros.

Pasando por alto la Sociedad Económica que José Celestino Mutis fundara en Bogotá en 1801, y la de Mompós, ${ }^{33}$ el primer intento importante de asociación literaria lo hizo el sabio Antonio Nariño en unión de Antonio Zea, José Antonio Ricaurte y José Lozano; Nariño inició en su propia casa, en 1789, un círculo literario que duró hasta 1794. La personalidad de Nariño y su rica biblioteca contribuyeron a la poderosa influencia que dicho grupo ejerció en los jóvenes literatos de aquel tiempo. Entre éstos asistían al círcu1o José Luis Azuola, Francisco Tovar, Luis Azuola, Joaquín Camacho, cierto Iriarte y otros de menor nombradía. En 1791 se fundó otra tertulia en Bogotá, llamada Tertulia Eutrapélica, fundada por Manuel del Socorro Rodríguez, y entre sus miembros más destacados se cuenta a José María Valdés, poeta festivo que amenizaba la tertulia con chispa y sal, José María Gruesso y otros. Algunos de los socios de esta tertulia publicaban artículos y poesías en el Papel Periódico (1791-1797). Resultado de la influencia literaria y política de La Miscelánea (1825), cuyos redactores eran José Angel Lastra, Pedro Acevedo, Rufino Cuervo, Alejandro Vélez y Juan de Dios Aranzazu, fué la organización de la Academia Nacional de Co- 
lombia en 1826 , compuesta de veintiún individuos de número y de correspondientes. El Parnasillo, empezado en 1830, fué una congregación de jóvenes intelectuales bogotanos que se reunían en casa de los contertulios, como Juan Antonio Marroquín, los Caro, José María Saiz, Félix Castro y otros. El Liceo Granadino, fundado en 1856 por iniciativa de José Joaquín Ortiz, consagró parte de sus esfuerzos a la propagación y desarrollo de las bellas artes y la literatura.

De suma importancia e influencia en la vida literaria bogotana fué la famosa Academia del Buen Gusto, que florecía a fines del siglo pasado. Estaba patrocinada por la distinguida dama doña Mantela Santamaría de Manrique, quien no sólo era literata, sino una naturalista de primer orden. La tertulia se reunía en su propia casa, frecuentada por los ingenios más notables de la época, tales como el fecundo Manuel del Socorro Rodríguez, ya mencionado, quien, según Vergara y Vergara, ${ }^{34}$ introdujo en Colombia el periodismo político; Francisco Antonio Ulloa, escritor naturalista; Francisco José de Caldas; José María Salazar, dramaturgo y educador; Camilo Torres, ilustre patricio; Custodio García Rovira; Frutos Joaquín Gutiérrez; José Fernández Madrid y otros ilustres contemporáneos. José María Salazar, al hablar de José María Gutiérrez, dice que éste "dedicaba el tiempo del descanso, con otros jóvenes provechosos, a una junta privada llamada del Buen Gusto. Allí se estudiaba la historia y otros ramos de literatura, se componían discursos y poemas, estimulados por premios de honor propuestos por los protectores de esta virtuosa sociedad, y todos sus miembros han figurado después en los destinos públicos". ${ }^{35}$

En el Ecuador, o mejor, en la región de Quito, el interés cultural en tiempos coloniales fué mayormente científico, pero los estudios ejercieron vasta influencia en las letras de esa parte de los Andes. Se encauzan los estudios por este ramo del saber humano, principalmente por la influencia extranjera en aquella época. La llegada en 1735 a dichas tierras de hombres de ciencia, miembros de la Academia Francesa, sabios como Bouguer, La Condamine, Jessieu, Seniergues, Godin, Verguin, y algunos españoles, como Antonio de Ulloa y Jorge Juan; la presencia de estos hombres de ciencia, venidos para estudiar y medir el meridiano y figura de la tierra, despertó vivo interés cultural entre los afanosos por las letras y ciencias. La vida intelectual estaba en una situación angustiosa y la llegada de esos cultos académicos levantó la cultura nacional a un 
nivel muy respetable, especialmente en las ciencias astronómicas y físicas. Como resultado del empuje dado a tales estudios se fundó en Quito la Academia Pichinchense, ${ }^{36}$ que produjo tres grandes ingenios: Javier de Santa Cruz y Espejo, médico cirujano y eminente hombre de ciencia, Juan de Velasco y Juan Bautista Aguirre, expulsado jesuíta ecuatoriano que llegó más tarde a ocupar importantes cargos. El ya mencionado Mutis también se identifica con el grupo de sabios de Quito. Es José Celestino Mutis, seguramente, el más grande sabio hispano de su tiempo. Por su iniciativa se fundó en Quito, en noviembre de 1791, la Sociedad Patriótica de Amigos de Quito, cuyo presidente era el Obispo Pérez Calamar, y Espejo su secretario. Dicha Sociedad se interesaba por todos los aspectos culturales, como se ve al examinar Primicias de la Cultura de Quito, órgano de dicha Sociedad, cuyo primer número apareció el 5 de enero de 1792. ${ }^{37}$ Además de su contribución como naturalista, Mutis ejerció influencia poderosa al despertar el interés científico y literario en algunos de sus asociados de estudio y tertulia, como es el caso del colombiano Caldas.

E1 viaje del Barón Alejandro von Humboldt, en 1801, a Quito y por toda la América, también fué otro impulso a las letras y ciencias.

En Lima las tertulias y sociedades literarias se remontan a épocas más lejanas que las ya estudiadas. Uno de los primeros círculos literarios de interés mayor en la capital del Perú fué la Academia. Antártica, tertulia literaria de que poco se sabe hasta ahora. Menéndez y Pelayo ${ }^{38}$ cree que era esta Academia la misma Universidad de San Marcos. El sevillano Diego Mexía era socio de dicha organización; se daba el nombre poético de "Delio". En su Primera parte del Parnaso Antártico de obras amatorias, 1608, tiene varios poemas ensalzando la tertulia. Pedro de Oña escribe sonetos laudatorios En nombre de la Antártica Academia de la Ciudad de Lima en el Perú. También se tienen noticias de que cierto licenciado Francisco Falcón era su presidente, y un tal capitán Salcedo Villandrado, que se daba el nombre de "Cirselio", entre otros, formaba parte de esta Academia.

E1 Príncipe de Esquilache, don Francisco de Borja y Aragón, Virrey del Perú de 1615 a 1622, fué un culto gobernante interesado en establecimientos de enseñanza y en el progreso intelectual de su reino. A su instigación se fundó en Lima el Real Convictorio de San Bernardo, para la educación de los hijos de los conquistadores, y 
otros centros docentes. Mendiburu dice que el Príncipe de Esquilache también era protector de las letras.

Como amante de las letras no era posible que Esquilache pasara sin fomentarlas y sin rodearse de los ingenios más distinguidos que ofrecía Lima en tan remota época; y así se reunían semanalmente, en Palacio, diferentes personajes a cuyos estudios se agregaba la ilustrada capacidad que enaltecía su mérito. El coronel D. Pedro de Yarpe y Montenegro, el oidor D. Baltasar Illescas, de la Orden de San Francisco, el poeta D. Baltasar Moreyra, y otros que no nombramos por falta de noticias, tenían con el virrey discusiones sobre materias científicas; cultivando su saber literario con los ensanches que en sus debates académicos avivaban la más noble de las aspiraciones. 39

Menéndez y Pelayo duda de la existencia de la tertulia de Esquilache, ${ }^{40}$ aunque la mayoría de los críticos no dudan lo dicho por el general Mendiburu. Esperamos que este y otros detalles se aclaren con el tiempo. Lo que sí se sabe con certidumbre es que el Príncipe de Esquilache era conocedor por propia experiencia de tales reuniones literarias, pues había tomado parte en semejantes tertulias en España, donde había disfrutado de prestigio literario. También se sabe que era amante de las letras y que tenía salón nocturno en su palacio para solazarse con acrósticos, acertijos y otras formas poéticas entonces muy en boga. Tal vez leyó en su tertulia sus epístolas morales $\mathrm{y}$ sus sonetos.

Tertulia de mayor consecuencia y de la que se tienen noticias más abundantes y fidedignas, es la patrocinada por el Marqués de Castell-dos-Rius, don Manuel Oms de Santa Pau de Sentmanat y Lanuza, Virrey del Perú. Se reunía todos los lunes por la noche en el palacio y en la casa de campo del Virrey. Duró desde el 23 de septiembre de 1709 hasta el 24 de marzo de 1710, es decir, hasta la muerte de su protector. Concurrían a dicha tertulia literaria los ingenios más notables de aquella época: el doctor Pedro José Bermúdez de la Torre y Solier, alcalde mayor de la Real Audiencia de Lima; el Marqués de Brenes, antiguo gobernador de Tierra Firme; Juan Manuel de Rojas, secretario del Virrey; el presbítero Miguel Sáenz Cascante, poeta de gran humor; el célebre y docto Pedro de Peralta Barnuevo; Fray Agustín Sanz y otros. El Marqués mismo era aficionado a la poesía, traductor del latín, y aun tocaba la guita- 
rra entre sus intimos. También le gustaba la representación de comedias.

La poesía de la tertulia del Marqués de Castell-dos-Rius, y la de aquella época, se caracteriza por su artificialidad y conceptismo. Cueto, al hablar extensamente sobre la citada tertulia, dice:

Acaso por el aislamiento en que vivían los poetas en aquellas apartadas regiones, el cultismo ni subió a las nebulosas alturas de los Góngoras, ni descendió a la ruin y repugnante esfera de los Montoros. Los asuntos académicos son unas veces nobles y naturales, como, por ejemplo, a la victoria alcanzada por Felipe $\mathrm{V}$ en la batalla de Luzzara; otras, las más, son de aquellos que ponen en prensa el ingenio y provocan los juegos de metro y de palabra, los retruécanos y los conceptos. 41

En la misma época que florecía la tertulia literaria del Marqués de Castell-dos-Rius había otras asambleas literarias en Lima dignas de mención. Una de ellas era la Tertulia del Marqués de Villafuerte, fiscal de la Audiencia, quien fomentó en su casa una de estas asociaciones. El doctor Domingo Orrantia, consejero de Indias, juez y hombre de alto prestigio en el Perú, en compañía de su culta y sabia hermana doña Manuela, fomentaba en Lima el gusto por las letras. Según Mendiburu, "la casa de Orrantia en Lima fué en una época punto de reunión de literatos y personas del más fino trato". ${ }^{42}$ Keunión también en casa particular fué la conocida hasta ahora sólo con el nombre de Segura. Parece que fué de algún prestigio dicha reunión, pues asistían hombres de la talla de Felipe Pardo, Miguel del Carpio, Manuel Ferreyros, José María Seguín e Ignacio Novoa. ${ }^{43}$

La Academia Filarmónica de Lima, fundada en 1787 por don José Rossi y Rubí, se convirtió tres años más tarde en la Sociedad Amantes del Pais, la que fué reconocida oficialmente por Real Decreto del 19 de octubre de 1792. Su presidente fué José Baquíjano, y el secretario Hipólito Unánue. Publicaba dicha organización el influyente Mercurio Peruano, periódico enciclopédiço, cuyo redactor era Jacinto Calero. Con esta publicación bisemanal, que se publicó de 1791 a 1793, la Sociedad ejerció una influencia trascendental en la vida intelectual del Perú. Inició la reforma de los estudios científicos y literarios. Los libros prohibidos llegaban a las manos de los redactores del. Mercurio Peruano, los que facilitaban la introducción de nuevas ideas y progreso científico y filosófico. Fué por medio 
de la Sociedad Amantes del País como el Barón Timoteo de Nordenflich, natural de Prusia, y un grupo de científicos alemanes dieron un verdadero impulso a los estudios científicos en el Perú, ${ }^{44}$ sobre todo a la metalurgia. La Sociedad estableció en Lima, en 1791, un laboratorio químico para la enseñanza de dicha materia a la juventud estudiosa.

Figura de gran prestigio y respeto en la Sociedad fué José Baquíjano, quien, con Unánue y Calero, había redactado el reglamento de la Sociedad. Baquíjano poseía una repleta biblioteca que los redactores del Mercurio usaban para sus escritos. Otros socios fueron Toribio Rodríguez de Mendoza, doctor Vicente Morales y Duares, fray Diego de Cisneros, ferviente enciclopedista, doctor Pedro Nolasco Crespo, sabio en las ciencias aplicadas, y Ambrosio Cerdán de Landa, presidente por algún tiempo de la Sociedad. Los miembros de ésta, especialmente los redactores del Mercurio, tal vez por motivos políticos, llevaban pseudónimos diversos. Unánue se firmaba Aristo, Baquíjano Cefalio, Rossi Hesperiófilo, Cisneros Arquidano, el doctor Cerdán de Landa Nerdacio.

A principios del siglo xix la juventud letrada de Chuquisaca, dirigida por Mariano Moreno, fomentaba el movimiento revolucionario. Las ideas de independencia habían sido sembradas en los jóvenes espíritus y sólo se esperaba el momento propicio para darles salida. Facilitaban la reunión y la discusión los gimnasios organizados y administrados por la Universidad. Eran éstos meras asambleas con estatutos propios, cuyos miembros eran estudiantes de jurisprudencia próximos a terminar su carrera. ${ }^{45}$ En una de tales sesiones disertó José Bernardo Monteagudo, el 25 de mayo de 1808, sobre "El origen de la Sociedad y sus medios de mantenimiento". Uno de estos grupos de jóvenes constituía la Academia Carolina.

La Sociedad Patriótica de Lima sirvió como centro de propaganda política, aunque también estaba revestida de forma de asociación literaria. Fundada por Bernardo Monteagudo el 20 de enero de 1822, tenía por fin, según sus reglamentos, "discutir todas las cuestiones que tengan un influjo directo o indirecto sobre el bien público, sea en materias políticas, económicas o científicas, sin otra restricción que la de no atacar las leyes fundamentales del país, o el honor de algún ciudadano". ${ }^{46}$ Para llevar esto a cabo había que instituir un buen sistema de educación pública en el país. No obstante tener la Sociedad una sección de bellas artes, que según el re- 
glamento incluía "antigüedades, historia, lenguas, poesía, oratoria, etc.", no llegó a discutir tales materias durante las veintidós sesiones que la agrupación tuvo, sino temas fundamentales propuestos por la presidencia, como "¿Cuál es la forma de gobierno más adaptable al Estado peruano, según su extensión, población, costumbres, y grado que ocupa en la escala de la civilización?" y otros por el estilo.

José María Pando ejerció influencia literaria en el gusto y destino de algunos jóvenes escritores de Bolivia, Perú y Chile con su tertulia literaria. Fué Pando preceptista y vigilante de las reglas del bien decir.

Chile ofrece un caso de especial interés. Por su posición geográfica y su desarrollo histórico, el desenvolvimiento intelectual moderno adquiere allí robustez en la época de Bello, Lastarria y la fundación de la Universidad de Chile, establecida en 1843. Por otra parte, Chile ha producido grandes historiadores, gramáticos, sociólogos e investigadores; el interés fué, pues, distinto de los otros países y más tardío. Las sociedades literarias de Chile no tuvieron la influencia que en otras partes de América, en su desarrollo intelectual, pues cuando eran conocidas en Lima, Quito y Bogotá, en Chile no existían. Pero como dice Medina: "Cierto es que bajo el nombre de concilios provinciales tuvimos varias asambleas de jentes más o menos ilustradas, pero fueron convocadas accidentalmente i con fines relijiosos i no literarios. Las letras chilenas no les fueron deudoras a este respeto sino de los monumentos escritos que nos dejaron en forma de códigos teolójicos." 47 Durante los primeros años del siglo xix el ambiente de Chile no era propicio para la producción literaria. Sin embargo, la personalidad de José Joaquín de Mora descuella entre los incipientes de las letras de Chile.

Aunque el nombre de Mora se identifica con otros países, este español de América dejó sentir su influencia primero en Chile. Aquí organizó en su propia casa una academia literaria a la que asistían representantes políticos de todas facetas. Tales reuniones produjeron en Chile movimientos intelectuales que pronto tuvieron considerable efecto en la literatura y pensamiento del resto del continente, pues Mora fué, si no el precursor, por lo menos un atrevido iniciador del romanticismo y un adalid de la libertad del sentimiento y de la imaginación. Mora era liberal; colaboró en El Mercurio Chileno y sus ideas e influencia fueron de verdadero significado. Los conser- 
vadores, para contrarrestar la influencia de Mora 1levaron a Chile a Andrés Bello, quien en literatura y en política representaba todo lo contratio a Mora.

E1 año 1842 fué una fecha de gran significado intelectual en Chile, pues en ese año José Victorino Lastarria fundó la Sociedad Literaria en cuya apertura el fundador pronunció un elocuente discurso sobre regeneración literaria. Al principio dicha Sociedad era concurrida mayormente por estudiantes. La llegada de los enigrados argentinos Sarmiento, Alberdi y López promovió una polémica literaria que produjo frutos beneficiosos. Los argentinos sostenían que en Chile no había literatos y para demostrar tal falsedad los jóvenes ingenios chilenos se apresuraron a producir.

Lastarria fundó el Semanario Literario en 1842, en el cual colaboraron casi todos los escritores jóvenes de aquella época. Después fundó El Crepúsculo, otro influyente periódico semanal literario. En estos dos periódicos aparecieron muchos trabajos de los socios de la Sociedad Literaria; en efecto, El Crepúsculo era el órgano oficial de la Sociedad. En 1848 fundó Lastarria la Revista de Santiago, publicación de alto respeto, y en 1859 estableció el Círculo de los Amigos de las Letras, entidades que, con el establecimiento de la Academia de Bellas Artes en 1873, dieron un verdadero empuje a las letras de Chile.

En el Uruguay la actividad literaria se inició también bastante tarde, por su remota distancia de las más prósperas cortes literarias. Los primeros ensayos empezaron en el siglo xviII y adolecían de la misma decadencia que se ve en los círculos literarios de las otras. capitales. Aunque hay círculos anteriores, el primero de más relieve en el Uruguay es el que el periódico El Nacional ${ }^{48}$ organizara en Montevideo en 1841, siendo José Rivera Indarte su redactor. Era. la redacción de este periódico centro de reunión de los hombres de letras de Montevideo. Concurrían a las tertulias literarias Juan Carlos Gómez, joven pocta de gran promesa que llegó a ser abogado, tribuno, ministro y legislador y a cuya residencia se trasladó dicha tertulia; los argentinos asilados Juan Cruz Varela, José Mármol, José María Gutiérrez y Esteban Echeverría; los vates Juan Bautista. Alberdi, Francisco Javier de Acha, Alejandro Magarinos Cervantes y Enrique de Arrascaeta. La Gaceta del Comercio fué el órgano oficial de esta tertulia. 
El Ateneo de Montevideo, fundado en 1872, era el centro de la cultura del país en donde se reunía la intelectualidad contemporánea. ${ }^{49}$ Se 1lamó al principio Club Universitario y floreció entre 1880 y 1885 . En ese entonces Melián Lafinur recitaba sus vigorosos versos en aquel recinto; allí se oía la poesía de Sierna y Carranza; y por sus salones pasaron Manuel Otero, Pedro Bustamante, Washington P. Bermúdez, Daniel Muñoz, Juan Carlos Blanco, Aureliano Rodríguez Larreta, Domingo Aramburú, Martín C. Martínez y otros.

El café, los salones, la botica y la librería han sido siempre favoritos lugares de reunión de los literatos o aficionados a la literatura. $\mathrm{E}$ l café es un factor de gran consideración en la producción literaria. de los pueblos hispanos. Es en las tertulias del café donde el incipiente literato o poeta recita sus versos, antes de consagrarlos a la estampa. En España algunos de los mejores trozos literarios de los siglos XIX y $\mathrm{xx}$ han sido leídos o recitados en el café antes de ver la. Iuz pública. Larra, Espronceda, García Gutiérrez, Bretón de los Herueros, Mesonero Romanos y Hartzenbusch hicieron del café centro. célebre de reunión y lo ha sido desde entonces en adelante, tanto en España como en América, especialmente en Madrid y las capitales hispanoamericanas. La costumbre de reunirse en el café para charlar de asuntos literarios data de fines del siglo xvin, y marca dicho establecimiento, con sus peñas, tertulias y saloncillos, la transición de la academia de aspecto culto y serio a la asamblea con más libertad y de carácter semipúblico.

Faltan por estudiar las noticias sobre las tertulias en los cafés de las capitales virreinales. Se establecieron los cafés en la Colonia. a últimos del siglo xviII, pero han ejercido en la Argentina mayor influjo que en México y Lima. En Buenos Aires, como en Madrid, el café ha sido siempre un punto vital en la vida y desarrollo intelectual del país. Uno de los más célebres cafés de Buenos Aires fué el Café de Marcos, que parece ya existía en 1799 y que en 1810 se convirtió en Sociedad Patriótica. Frecuentaban esta sociedad los jóvenes abogados, curiales, dependientes de comercio y otras personas de la clase acomodada. El Café Catalanes fué otro establecimiento de vida larga y próspera en Buenos Aires; duró de 1800 hasta 1873 y era sitio popular de reunión de los literatos. Al Café Inglés de Keen y Faunch acudían Bernardino Rivadavia, Valentín Gómez y Alvear, Juan Cruz Varela y otros en 1823, y el Café de la Comedia: 
era la antesala del teatro donde el célebre cómico Joaquín Culebras entretenía a su auditorio con gritos y exagerados ademanes.

En el fragor de la lucha por la independencia, Buenos Aires contaba con elegantes salones literarios, frecuentados por los revolucionarios y héroes más famosos de entonces. Baste recordar por ahora las tertulias auspiciadas por Mariquita Sánchez, la de Josefina Izquierdo y el Salón de Carmen Nóbrega de Avellaneda.

Célebres centros de reunión revolucionaria fueron la Botica del Colegio, de Francisco Marull, cuyos concurrentes estaban en favor del gobierno español, la Botica de Amoedo, la de Ferrari, la de Demarchi, la de Pedro Murray, cuyos dueños eran hombres instruídos y respetados por los socios que honraban sus establecimientos. Concurrían a la tertulia del librero y editor Carlos Casavalle hombres de Estado, ministros, periodistas, escritores y militares, hombres de la talla de Juan María Gutiérrez, Bartolomé Mitre, Vicente G. Quesada, Guido Spano, Rafael Obligado, Paul Groussac y otros de no menos valía.

El coronel Francisco Antonio Cabello y Mesa propuso al Real Consulado de Buenos Aires, el 26 de noviembre de 1800, la erección de una Sociedad Patriótica Literaria y Económica. Más tarde presentó Cabello el proyecto de los estatutos de su Sociedad y también la nómina de la mesa directiva de la misma. ${ }^{50}$ Pero cuando el virrey Marqués de Avilés examinó el oficio de Cabello pidiendo ayuda económica para la Sociedad, dictó en contra de dicha medida. La Sociedad había de ser de carácter patriótico, literario y económico. Como es de esperarse, El Telégrafo Mercantil, primer periódico argentino, fundado en 1801, también por Cabello y Mesa, sería el órgano de la agrupación. En efecto, ya al solicitar licencia para publicar dicho periódico se refería Cabello a la Sociedad literaria que intentaba establecer.

Aunque tenemos los nombres de las personas que integraban la mesa directiva de la Sociedad, y a pesar de haber indicaciones de que ciertos escritores concurrieron a reunión o reuniones de dicho círculo literario, no se está todavía enteramente de acuerdo sobre si la mencionada Sociedad funcionó después de los intentos de su fundador. Lo más probable es que no llegara a realizarse el proyecto del coronel Cabello y Mesa.

La Sociedad Literaria de Buenos Aires fué obra de Bernardino Rivadavia, quien siendo Ministro encargó a dicha entidad, en 1822, 
la compilación de todas las poesías patrióticas publicadas desde 1810, dos años antes de la fundación, hasta aquella fecha. El resultado fué la Colección de poesías patrióticas, aparecida como anónima y sin fecha, aunque el encargado de la colección fué Esteban de Luca, quien la publicó en Buenos Aires en 1827. ${ }^{51}$ Otros miembros de la Sociedad fueron el poeta Rivarola, el porteño Domingo de Azcuénaga y José Joaquín de Arango, quien también parece haber sido socio de la tertulia de Cabello y Mesa.

La Sociedad del Buen Gusto en el Teatro fué fundada en 1817 bajo los auspicios del coronel Juan Román Rojas, para fomentar los espectáculos escénicos. Formaban parte del grupo fray Camilo Henríquez, nacido en Chile, educado en Lima y emigrado a Buenos Aires, Esteban de Luca, patriota revolucionario ya mencionado, y Vicente López y Planes, autor del primer Himno Nacional de la Argentina. Parece ser que la asociación no tuvo gran originalidad. Se tradujeron algunos dramas de poco significado y se estrenaron algunas piezas compuestas por algunos de sus miembros, entre las que sobresale Camila o la patrona de Sudamérica (1817), de Camilo Henríquez, pieza que versaba sobre la inmigración europea.

La literatura argentina se halla impregnada del espíritu separatista. Juan María Gutiérrez, el biógrafo de Echeverría, ya lo dice: "En la atmósfera general de aquella época, las formas literarias no fueron en su novedad otra cosa más que la expresión adecuada y natural de un movimiento en la raíz de los espíritus, producido por la influencia de la libertad que comenzaba a disfrutar más ampliamente." 52 Para ese tiempo las ideas filosóficas y políticas habían encontrado caluroso abrigo en el ardiente espíritu revolucionario de la juventud rioplatense y la restauración temporal de los jesuítas, en 1814, no pudo proscribir o retardar el continuo progreso del movimiento de libertad de la región. Sitio predilecto de reunión de estos jóvenes literatos y patriotas fué la trastienda del librero y bibliógrafo Marcos Sastre. En el ensanchado cuarto trasero del establecimiento se inauguró en 1836 el Salón Literario, concurrido por Alberdi, Cané, Gutiérrez, Fidel López, Echeverría y otros.

En su primer año de vida, el Salón Literario se consagró por completo a asuntos literarios. Echeverría era su poeta romántico y portaestandarte. Aquí también hablaron Alberdi, Gutiérrez, Marcos. Sastre, López, etc., sobre materias literarias, pero se siente un constante deseo de discutir ideas políticas. Al año siguiente Marcos Sas- 
tre se vió obligado a cerrar stu establecimiento, pero pronto fundó una sociedad secreta en donde los socios pudieron continuar el desarrollo de avanzadas ideas libertadoras. Dicha sociedad se llamó la Joven Argentina y fué fundada el 23 de junio de 1837. Echeverría fué su primer paladín, como lo había sido en la anterior. Su principal objeto era la liberación de los pueblos, la fraternidad e igualdad de las clases, el progreso, etc. ${ }^{53}$ Fruto directo de tal sociedad secreta fué la influencia en el ánimo de los jóvenes de aquella época, jóvenes que más tarde llegaron a ser los grandes pensadores y guías del país, genios como Mitre y Sarmiento. En tiempos más recientes ha habido muchas otras excelentes sociedades literarias, algunas de las cuales todavía existen. Otras han desaparecido, pero su influencia en las letras ha sido de considerable valor. El Círculo Literario dirigido por Vicente G. Quesada, cuyo órgano era la Revista de Buenos Aires, es ejemplo de los muchos importantes centros literarios que han florecido en la Argentina.

Allá por los comienzos de la segunda mitad del siglo xviII el Brasil empieza a desenvolverse rápidamente y a adquirir personalidad propia, gracias a la explotación de sus minas de oro y diamantes, a la sabia administración del Marqués de Pombal y a su desarrollo comercial. Este nuevo rumbo había de obrar en los ánimos de los escritores y de acentuar más el espíritu brasileño. Bahía fué al principio el centro comercial e intelectual de la Colonia. Por eso encontramos en dicha ciudad la primera sociedad literaria en 1724, desde cuya fecha en adelante las sociedades y círculos literarios del Brasil se multiplican. Aquí, como hemos hecho tratándose de los demás países, mencionaremos los más importantes.

La Academia Brazilica dos Esquecidos, es decir, de los olvidados, funcionaba ya en Bahía en 1724 , bajo la protección del virrey Meneses. Duró escasamente un año y medio, durante cuyo tiempo celebró dieciocho sesiones en las que se estudió la historia del Brasil especialmente. La Academia dos Felizes, fundada en Río por el doctor Matheus Saraiva el 6 de mayo de 1736, compuesta de treinta miembros, se dedicaba a los estudios de botánica. Se retunía en el palacio del Conde de Bobadella, capitán general del país. La Academia dos Selectos, fundada en 1752, estaba consagrada casi exclusivamente a cantar las gentilezas del mencionado capitán general, Conde de Bobadella, ${ }^{54}$ cuyo primer nombre era Gomes Freire de Andrade. También se reunía en el palacio del Conde. Protegida por el virrey 
Luis Almeida, Marqués de Lavradio, ferviente amante de las letras y ciencias, la Sociedade Literaria, fundada en 1772, fué la primera sociedad de alguna importancia en el Brasil. Las que le precedieron servían para allanar el camino a esta sociedad y a otras de más tarde. Con la Sociedade Literaria empezó en Río y en el Brasil un nuevo período de literatura nacional, no sólo debido a la influencia de dicho centro, sino al enciclopedismo francés que transformó el verbo intelectual brasileño.

Por la misma época se fundó en Bahía la Sociedade Brasileira dos Academicos Renascidos, que dejó de existir al poco tiempo. Su presidente fué José Mascarenhas Pacheco. Estaba dicho círculo interesado en la historia del Brasil. La historia natural también recibió un poderoso impulso con el establecimiento en Río, en 1784, del Gabinete de Estudos de Historia Natural.

En 1786 se fundó allí mismo la Arcadia Ultramarina, a imitación de la Arcadia italiana, y entre sus socios se contaban el mismo virrey don Luis de Vasconcellos y Sousa, Manuel Ignacio da Silva Alvarenga, el alma de la sociedad, Bazilio da Gama, el obispo José Joaquín Justiniano Mascarenhas, Castello Branco, Bartholome1 Antonio Cordomes, Domingo Vidal Barbosa, Balthasar da Silva Lisba y otros. ${ }^{55}$ Cerró sus puertas la Arcadia Ultramarina a los cuatro años, pero volvió a abrirlas en 1794, para ser clausuradas definitivamente por el sucesor de Lavradio, el Conde de Rezende, a pretexto de que era un club de jacobinos. Otra Arcadia del mismo tiempo fué la Arcadia Fluminense Franciscana, que celebraba sus sesiones en el convento de la orden seráfica de Río. Los frailes recitaban sus versos en las reuniones.

A comienzos del siglo xx existía el Gremio Literario Jardim de Academus, compuesto de veinte miembros. Domingo da Gama, novelista, diplomático y ministro, fué presidente perpetuo, honor conferido a los dieciocho años de edad. Publicaba esta tertulia literaria la Gazeta de Noticias. Muy vinculada al desarrollo intelectual del Brasil se halla la Sociedad Auxiliadora de la Industria Nacional, fundada en Río en 1828 por don Ignacio Pinto de Almeida. Resultado de esta Sociedad fué la creación en 1838 del Instituto Histórico y Geográfico del Brasil, una de las mejores instituciones del mundo. En Bahía existía en 1860 el Gremio Literato, y en Río se fundó en 1883 la Sociedad de Literatos, compuesta de Juan Severiano de Fonseca, Sousa y Silva, Ladislao Netto y otros. A fines del siglo xix los lite- 
ratos, por falta de centros de reunión, se asociaban con los periodistas y formaban núcleos literarios algunas veces de verdadera influencia literaria. Tal fué el caso de la tertulia literaria formada de literatos y redactores de periódico auspiciada por la Gazetinha, así como el círculo literario que se reunía en la redacción de la Semana. En los salones de redacción de la Revista Brasileira se congregaban los mejores literatos de fines del siglo XIx, donde Machado de Assis era la figura central. Aquí se acostumbraba a servir té con tostadas a las cinco y fué a resultas de tales reuniones intimas y también por las gestiones de Lucio de Menđonça como se concibió la creación de la Academia Brasileira de Letras, compuesta de cuarenta miembros. Al cesar la Revista Brasileira la casa editorial Garnier ofreció refugio a los miembros de esta tertulia, la que, como se ve, fué próspera e influyente.

José SÁnchez, Northwestern University.

\section{NOTA S}

1 Véase mi artículo "Nombres que reemplazan a 'capítulo' en libros antiguos", Hispanic Review, XI (abril, 1943), pp. 143-161.

2 Preparo un estudio de mayor extensión, Sociedades y academias litetatias de España e Hispanoamérica.

3 Cfr. Academia Nacional de Ciencias Antonio Alzate, México; Sociedad Mexicana de Geografía y Estadística, etc.

4 Ricardo Rojas, La literatuta atgentina, 8 tomos, Buenos Aires, 1924 25, tomo IV, pp. 630-45.

5 Ozías H. Rubio y Manuel Briceño, Tunja, Bogotá, 1909, pp. 76-102.

6 Irving A. Leonard, Pedto de Peralta Barnuevo, Santiago de Chile, 1937, p. 14 .

7 Cartel de certamen, el nuevo héroe de la fama, Lima, 1762.

8 Antonio Bachiller y Morales, Apuntes para la historia de las letras y de la instrucción pública de la Isla de Cuba. 3 vols., Habana, 1859-61, tomo II, pp. 79-102. 
9. José María Vergara y Vergara, Historia de la litetatuta de Nueva Granada, 3ạ ed., Bogotá, 2 vols., 1931, tomo II, p. 135.

10 Francisco Pimentel, Historia crítica de la litetatura $y$ de las ciencias en México, 5 vols., México, tomo I.

11 Cfr. Bachiller, op. cit., III, p. 41.

12 Aurelio Mitjans, Estudio sobre el movimiento científico y literatio de Cuba, Habana, 1890, p. xxviii.

13 José Antonio Saco, Colección de papeles cientificos, históricos, politicos y de otros ramos sobre la isla de Cuba, ya publicados, ya inéditos, 'París, $1858-59,3$ vols:, véase III, pp. 1-84.

14 Mitjans, op. cit., p, 107; y Bachiller, op. cit., II, pp. 113-144.

15 Historia de la Poesía Hispano-Americana, Madtid, 1911-13, 2 vọls., véase I, p. 227, nota 2 .

16 Real Orden. Ministro de Fomento General del Reino, en Bachiller, op. cit., II, pp. 200-201.

17 Saco, op. cit., III, pp. 1-84.

18 Habana, 1866.

19 Luis Aiberto Sánchez, Historia de la literatura americana, 2 à ed.s Santiago de Chile, p. 350.

20 Menéndez y Pelayo, op. cit., I, 308.

21 Pedro Henríquez Ureña, Horas de estudio, París, 1910, p. 193.

22 Leopoldo Augusto de Cueto, Marqués de Valmar, Historia ctítica de la poesía castellana en el siglo XVIII, 3ạ ed., Madrid, 1893, 3 vols., véase I, p. 83.

23 En su obra Biblioteca hispano-ameticana septentrional, México, 1883. 3 vols., véase I, p. 180 .

24 Establecida por Real Orden del 25 de diciembre de 1783.

25 Flot de mis recuetdos, México, s. f., p. 423.

26 Cfr. José T. de Cuéllar, "La literatura nacional", La Ilustración Potosina, II (1869), pp. 162, 188 .

27 De mucha utilidad es el excelente artículo del profesor J. R. Spell, "Mexican Literary Petiodicals of the Nineteenth Century", en Publications of Modetn Language Association of America, tomo 52 (marzo, 1937), pp. 272-312.

28 David Vela, Literatura guatemalteca, Guatemala, 1943, p. 175. 
29 El Guatemalteco, año VI, núm. 248, 23 de octubre de 1879.

30 En Cuba la "Asociación Cultural Universitaria" empezó a publicar en 1917 otro Hotizontes, "Revista cientifica, literaria y social".

31 Roland D. Hussey, Traces of French Enlightenment in Colonial Hispanic America, en Latin America and the Enlightenment, editado por Arthur P. Whitaker. New York, 1942; y Jefferson Rea Spell, Rousseau in the Spanish World before 1833, Austin, Texas, 1938.

32 Vergara y Vergara, op. cit., II, p. 52.

33 Existía esta entidad en 1784, fundada por decreto del 17 de agosto del mismo año. En 1826 se fundó en Bogotá la Sociedad de Amigos del Pais. con las mismas miras patrióticas ya conocidas.

34 Op. cit., II, p. 21.

35 José María Salazar, Memoria biográfica sobre Cundinamarca, citado por Vergara y Vergara, op. cit., II, p. 93.

36 Cfr. Dionisio Alcedo, Diccionario geográfico e histótico de las Indias Occidentales o América, Madrid, 1788. También: Pablo Herrera, Ensayo sobre la historia de la literatura ecuatoriana, Quito, 1927.

37 José Toribio Medina, La imprenta en Quito, Santiago de Chile, 1904, pp. $68-74$.

38 Op. cit., II, pp. 169, 310.

39 Manuel de Mendiburu, Diccionatio histótico y biográfico del Perú, 8 vols., Lima, 1874-87, II, p. 50.

40 Op. cit., II, p. 183 , nota 1.

41 Leopoldo Augusto de Cueto, Marqués de Valmar, op. cit., p. 86.

42 Op. cit., vi, p. 184: también. Menéndez y Pelayo, op. cit., II, p. 199. nota 1.

43 José de la Riva Agüero, Catácter de la literatura del Perú independiente, Lima, 1905, pp. 71-73.

44 Marius André, Le Baron de Nordenflicht, Conseiller intime de S. M. le Roi de Pologne et les mineurs allemands au Pérou, en Revae de l'Amérique Latine, VIII (1924), pp. 289-306.

45 Cfr. Gabriel René-Moreno, Los últimos días coloniales en el Alto Perú, 2 vols., ed. de La Paz, 1940, tomo I, p. 79.

46 Manuel de Odriozola, Documentos literatios del Perú, 11 vols., Lima, 1863-1877, tomo XI, p. 490. 
47 José Toribio Medina, Histotia de la literatuta colonial de Chile, 3 vols., Santiago de Chile, 1878, tomo I, p. xliii.

48 Había sido fundado en 1835, por Andrés Lamas.

49 No se ha de confundir este Ateneo con el establecimiento de igual nombre fundado en Montevideo en 1837 por Luciano Lira, colector de la famosa antología Patnaso oriental.

50 А. M. Ibáñez, "Orígenes de la 'Sociedad Patriótica Literaria y Económica del Río de la Plata", 1800-1802", en Boletín del Colegio de Graduados de la Facultad de Filosofía y Letras, tomo IV (1934), pp. 5-9. Y José Torre Revello, "La primera sociedad literaria que se proyectó fundar en Buenos Aires". en La Prensa, 22 de octubre de 1939.

51 Revista del Rio de la Plata, II, p. 564.

52 Obras de Echeverría, 5 vols., Buenos Aires, 1870-74, tomo v, Introducción, p. xxiii.

53 Echeverría, "Ojeada retrospectiva", en El dogma socialista (1837). ed. de Buenos Aires, 1915, p. 33, nota 4.

54 Publicó esta academia los trabajos de sus miembros en 1754 , en Lisboa, con el título de Jubilos da Ametica na gloriosa exaltaçao e promoçao do Illmo. e Exmo. St. Gomes Freite de Andrade.

55 Eduardo Ferié, A litteratura brazileita, Buenos Aires, 1885, p. 185. 
